\title{
Effect of Nutrient Restriction on Social Transmission of Food Preferences Depends on Nutrient and Species
}

\author{
Darryl J. Mayeaux, Maxwell B. Wallace, Anne M. Young \\ Department of Psychology, St. Bonaventure University, New York, USA \\ Email: dmayeaux@sbu.edu
}

Received 10 October 2014; revised 27 November 2014; accepted 11 December 2014

Academic Editor: Juan J. Canales, University of Leicester, UK

Copyright (C) 2014 by authors and Scientific Research Publishing Inc.

This work is licensed under the Creative Commons Attribution International License (CC BY). http://creativecommons.org/licenses/by/4.0/

(c) (i) Open Access

\section{Abstract}

For omnivores to determine whether an unfamiliar item is an appropriate food, they could rely on personal information from sampling it themselves or rely on less risky observation of whether other individuals eat the item. Availability of information about food from social companions in group-living species is one of the benefits of group life. Adults of solitary-living species, however, seem typically less likely to rely on social information about food choice. If an individual faced a nutritional deficit, it would seem to increase the value of public information. This study addresses whether dietary restriction from certain nutrients (sodium, potassium, protein, carbohydrates) affects reliance on information about food from conspecifics. Without nutrient restriction, groupliving Norway rats (Rattus norvegicus) preferred the diet that they smelled on the breath of a conspecific demonstrator, but solitary-living Syrian hamsters (Mesocricetus auratus) avoided it. Protein restriction yielded similar results as measured one hour into a diet choice test. Potassium restriction, however, reversed the pattern: rats avoided the demonstrator's diet but hamsters preferred it. Clearly, the valence of social information depended on the nutrient from which individuals were restricted and the species under study. This could be related to the contrasting social organization that members of each species generate. Neither species relied on social information about the availability of a nutrient from which they were restricted if they could taste that nutrient for themselves (sodium, carbohydrates).

\section{Keywords}

\section{Social Learning, Dietary Preference, Nutrient Restriction}




\section{Introduction}

When animals select among habitats, among mates, or among food items, they risk making decisions without complete information about the relative value of the options available. Choices about food are especially important for omnivores. Unlike dietary specialists who can eat only a few foods, omnivores have the advantage of being able to subsist on a variety of foods. With this advantage comes risk when determining whether an unfamiliar item is a suitable food.

Information reduces uncertainty and risk. An omnivore may assess directly a new food's suitability and safety by sampling a small piece. That omnivore may also assess a new food indirectly through information inadvertently provided by others. Following from theoretical work on use of public information [1] [2], evidence of consumption by a conspecific could be sufficient to indicate a new food's suitability. Publicly available information lowers risk when ingesting unfamiliar food. Interestingly, public information and evolution of social learning [3] lead to the same prediction regarding when social information should be used: organisms should rely on public information when it's the less costly or the less difficult way to learn as compared to personal information from first-hand learning.

The wide availability of public information from social companions in group-living species is thought to be one of the benefits of group life [4]. Thus, it is not surprising that members of group-living species would learn from conspecifics when, where, and what to eat [5]-[7]. For example, when confronted with two foods with unfamiliar odors, rats prefer to consume the food with the odor that they smelled on the breath of the conspecific [8] [9]. When compared with species that are highly social, species that are more solitary would have fewer social companions and fewer opportunities for social interaction. In such species, the prevalence of socially-influenced diet choice is reduced and occurs primarily, but not exclusively, in young animals learning from parents [10][13]. Presumably adults of solitary-living species are less likely to rely on social information in food choice because their interactions with other adults would be infrequent.

If one of the benefits of group life is information exchange, it follows that public information would be particularly beneficial to those facing a nutritional challenge. Nutrient deficiency can occur in free ranging animals [14]-[16]. A nutrient deficiency may enhance the reliance on public information [17]. Animals' limited sensory capabilities also highlight the value of public information. Except for experiences of salty, sweet, or bitter tastes, there are no highly reliable sensory mechanisms to avoid toxins or to select quickly from available nutrients to match an individual's needs. Even after food is consumed, humans and other animals do not appear to be especially good at making immediate, or in some cases even longer-term, judgments and self-selecting foods based on whether these foods provide dietary requirements [18] [19]. Thus, an animal with a deficiency and with at best a modest capability to detect only some of the nutrients it needs in food would benefit greatly from public information on food choice and minimize the risk when trying new foods.

One question remains unresolved concerning public information and food choice by adults of a solitary species. Could a dietary deficiency make them more likely to rely on public information when selecting a food? To assess this, we selected one highly social species (Norway rats) and one solitary species (Syrian hamsters) for study. Although rats may rely on public information in dietary selection, hamsters tested in a similar circumstance did not show social learning of food preferences [12]. Because a fair amount is known about social behavior, olfaction, and learning in these two rodent species, they are good candidates for an initial comparison of the effects of nutrient restriction on species with contrasting social organizations.

A second question concerns whether for solitary species the use of public information in diet choice depends on the particular kind of dietary deficiency as it did for a social species [20]. Protein-deprived rats preferred to eat the food that they smelled on the breath of other rats. Sodium-deprived rats, however, were unlikely to prefer the food that they smelled on the breath of other rats. This difference in effect of the two nutrient deficiencies may have resulted because sodium deficient rats could learn by personal experience in one of two ways: through taste or through beneficial effects immediately after ingestion. Thus, the current study examines not only whether nutrient-deficient hamsters can be induced to prefer the diets that they smell on the breath of their conspecifics, but also whether any effect of nutrient deficiency on diet choice depends on the kind of nutrient deficit. Short-term deprivation of either protein, sodium, carbohydrates, or potassium allows determination of whether orosensory cues or immediate postingestive effects of foods were responsible for reduced reliance on less risky public information about diet choice. Sodium and carbohydrates provide robust taste cues that potassium and protein do not provide. This provides the rationale for the grouping of nutrients along the rows in Table 1 . So- 
Table 1. Nutrients selected for study.

\begin{tabular}{ccc}
\hline & \multicolumn{2}{c}{ Rapid postingestive effects } \\
\hline Orosensory cues & Yes & No \\
Yes & Codium & Carbohydrate \\
No & Potassium & Protein \\
\hline
\end{tabular}

dium and potassium, however, would have more rapid postingestive effects as compared to carbohydrates and proteins. This provides the rationale for the grouping of nutrients in the columns of Table 1.

The study described here adapts established methods used with several rodent species [8] [10]-[13] [20]. Rats and hamsters were fed either replete diets or were deprived for five days of one of the four nutrients in Table 1 . These subjects, who are observers, were then exposed across a wire mesh to a well-nourished conspecific, a demonstrator, who had eaten food flavored with either cinnamon or cocoa, novel odorants/tastants for the observer. This opportunity to inadvertently gain public information of olfactory dietary cues, a form of social learning, was followed by the opportunity for the observer to choose food from two cups. Those cups contained replete diet and were identical in all respects except for cinnamon flavor in one and cocoa flavor in the other. Proportion of diet consumed that was the same as that smelled on the breath of the demonstrator indicated the extent to which public information was used.

The present study makes an additional contribution by determining whether nutrient-deficient animals may have been generally hampered in their olfactory recognition ability. Presentation of social odors elicits sniffing of the odor. Memory for that odor is defined as a decrease in sniffing the odor across repeated presentations. If restriction from a nutrient had a general negative impact on recognition, then the decline across trials in investigation should be less dramatic when compared to the decline in investigation by animals with replete diets [21].

\section{Materials and Methods}

\subsection{Animals}

Adult male Norway rats (Rattus norvegicus) and Syrian hamsters (Mesocricetus auratus) were purchased from Charles River Laboratories (Wilmington, Massachusetts, USA) as non-siblings at 21 days of age. They matured in our laboratory, and testing began when they were at least three months of age. Because hamsters are typically solitary, we housed members of both species individually so that the species were comparable in this respect. Their plastic cages were $43 \mathrm{~cm}$ deep, $21 \mathrm{~cm}$ wide, and $20 \mathrm{~cm}$ high. The solid bottom was covered by Sani-Chips bedding (P. J. Murphy Forest Products, Montville, New Jersey, USA), and the top was a stainless steel wire lid that held standard rodent diet and a water bottle. Cages, lids, and water bottles were cleaned every two weeks. Rats and hamsters were in separate colony rooms that were maintained at approximately 22 degrees Celsius and $50 \%$ relative humidity and were on a 14:10 light:dark cycle with lights off at 10:30 AM eastern standard time. Before the start of the study, animals had unrestricted access to a replete diet (Harlan Teklad 2018, Madison, Wisconsin, USA) and to reverse osmosis water in their drinking bottles.

Animals (53 rats, 57 hamsters) fulfilled one or more of three roles in this study: observer, demonstrator, scent donor. If an animal fulfilled more than one role, it was to be scent donor before observer and/or observer before demonstrator. We obtained data from observers (28 rats, 27 hamsters). Food consumption of observers was recorded after they interacted with conspecifics termed demonstrators (28 rats, 27 hamsters) because demonstrators had consumed a diet with a particular flavor added. Olfactory investigation by observers was also recorded as they investigated bedding containing the scent of conspecific scent donors (25 rats, 3 used twice, 5 later used as observers, 6 as demonstrators, 1 as both in that order; 22 hamsters, 5 used twice, 8 later used as observers, 6 as demonstrator, 1 as both in that order).

\subsection{Special Diets for Testing}

All diets were obtained in powdered form from Harlan Teklad (Madison, Wisconsin, USA) were nutritionally complete except for the specific micronutrient or macronutrient that each lacked. Sodium-deficient diet (TD.07856) and potassium deficient (TD.88239) were $12.7 \%$ of calories from fat, $19.2 \%$ from protein, and $68.1 \%$ from carbohydrates. Carbohydrate-only (TD.02521), protein-only (TD.02523), and fat-only (TD.02522) contained the 
same vitamin and mineral mixes and were selected to be as similar as possible to the sodium- and potassiumdeficient diets. Carbohydrate-only or protein-only diet was mixed with the fat-only diet to create a mixture with $12.7 \%$ of calories from fat, thereby yielding protein-deficient and carbohydrate-deficient diets that provided the same percentage of calories from fat as did the sodium- and potassium-deficient diets. Flavored diets consumed by demonstrators and observers were pulverized standard rodent diet (Harlan Teklad 2018) with 1\% by weight of ground cinnamon (McCormick \& Co., Hunt Valley, Maryland, USA) or 2\% by weight of powdered cocoa (The Hershey Co., Hershey, Pennsylvania, USA) added [20].

\subsection{Apparatus}

Powdered diets were provided to subjects in round stainless steel cups (Drs. Foster Smith, Rhinelander, Wisconsin, USA) measuring $9.3 \mathrm{~cm}$ in diameter and $4.5 \mathrm{~cm}$ in height. A cup could be anchored in the corner of the cage by a stainless steel ring that mounted through the cage wall. We found in pilot work that although this system for presenting powered diet worked for rats, hamsters tended to climb into the cup and get powdered food in their hair. Thus, when these cups were presented to hamsters, a false bottom made of stainless steel reduced the depth of the cup to only $1 \mathrm{~cm}$. This shallower bottom reduced hamsters' climbing into the cup to get food as they would perch their front paws on the edge of the cup and eat.

Because hamsters may fight when exposed to a same-sex conspecific, social exposure of the observers and demonstrators of both species was accomplished in a social exposure cage that was the same type as the living cage but partitioned diagonally from the front corner to the opposite corner in the back with wire mesh providing 3.2-mm square openings. This prevented animals from fighting but still allowed them close proximity to sniff the face of another animal, which they did readily across the mesh.

Two grams of unbleached, carded cotton, a square approximately $10 \mathrm{~cm}$ on a side, was given to animals who served as scent donors in order to obtain their scent for subsequent presentation to observers. Animals incorporated this cotton into their bedding. That scented cotton bedding was presented to subjects in a rectangular wire-mesh bedding holder providing 3.2-mm square openings to sniff the bedding inside. The bedding holder measured $9 \mathrm{~cm}$ by $18 \mathrm{~cm}$ and $1.15 \mathrm{~cm}$ thick and could be opened to insert and then remove bedding. The lid was held closed with two jewelry clasps. A black plastic strip woven through the mesh bisected the long dimension into left and right halves that were essentially square.

\subsection{Design \& Procedures}

\subsubsection{Nutrient Restriction, Social Exposure to Demonstrator, and Diet Choice}

Subjects were assigned to one of five test conditions. One test condition allowed continued access to replete diet (6 rats, 5 hamsters) that was pulverized to powder to be comparable to the four nutrient-restricted diets, which were also powdered. Restriction from a nutrient allowed the evaluation of the effect of nutritional status on use of public information on diet choice. The remaining four conditions restricted subjects from one nutrient, either sodium (5 rats, 5 hamsters), potassium (5 rats, 5 hamsters), protein (6 rats, 6 hamsters), or carbohydrate (6 rats, 5 hamsters) (see Table 1). The particular nutrients selected for restriction allowed evaluation of two competing hypotheses regarding whether rapid postingestive benefits of smaller nutrients (sodium, potassium) or orosensory cues of taste (sodium, carbohydrates) reduced reliance on public information. If the rapid postingestive effect of needed nutrients reduced reliance on public information, then sodium- and potassium-deficient animals (left-hand column in Table 1) will feel rapid relief from deficiency and rely on public information less than do protein- and carbohydrate-deficient animals. If orosensory cues from the needed nutrients reduce reliance on public information, then sodium- and carbohydrate-deficient animals (top row in Table 1) will taste the nutrient that they need and rely on public information less than do potassium- and protein-deficient animals. This $2 \times 2$ crossing shown in Table 1 also allowed the assessment of any combined effect of levels of postingestive effects and orosensory cues.

The design for studying the influence of public information was based on the methods used by Galef and Whiskin [20] to study rats and was modified as needed to be appropriate for both rats and hamsters. Two of the eight experimental conditions in this study were the same as used in their study. Using similar methodology in the current study allowed a comparison to their pattern of results. For the first two days of the experiment, all subjects received pulverized Harlan Teklad 2018 to familiarize them with eating food in a powdered form. Starting on the third day, animals in the four nutrient-restricted conditions received their respective diets for a 
total of five days (days three through seven). Animals in the unrestricted group continued receiving regular diet that was pulverized.

The fifth through seventh days were preparation for and execution of the test for social learning of food preferences. Demonstrators had been acclimated to receiving replete diet in powdered form for a 60 min period on days five and six. On the seventh day, a demonstrator conspecific received for $60 \mathrm{~min} 20 \mathrm{~g}$ of powdered replete diet flavored with either cocoa or cinnamon. Visual inspection confirmed that all demonstrators had eaten a portion of the diet. Whether the demonstrator ate cocoa or cinnamon was balanced across subjects in each test condition. Immediately after that one-hour period, the demonstrator and observer, who were unrelated and otherwise unfamiliar, were placed on opposite sides of the mesh in the social exposure cage and remained there for $30 \mathrm{~min}$. While the observer was out of his living cage, Sani-Chips bedding was removed and replaced with paper towels. This was done because in pilot tests wood chip bedding would end up in the food cups of the observers. Because the weight of food cups containing food was used to determine amount of food consumed, it was necessary to remove the wood chip bedding to reduce the bedding's extraneous influence on the measurement of the weight of the food cup. Immediately after this 30-min social exposure, the observer was returned to his living cage. He was able to choose between eating either of two replete diets that had been pulverized; one had cinnamon added and the other had cocoa added. Whether the demonstrator's diet was in the front or back of the observer's home cage was balanced across subjects within each test condition and across the type of diet the demonstrator ate. Weights of both food cups were measured 1 and 4 hrs after initial access was given. The change in the weight of the food cup from the start of the test indicated the amount of each food that was consumed. At the end of this test, the observer was given a clean cage with Sani-Chips bedding and regular rodent diet.

\subsubsection{Investigation of Cotton Bedding with Conspecific's Scent}

Days five and six were preparation for and execution of the non-associative learning task. To examine the hypothesis that any nutrient restriction would have had a general negative impact on recognition, we measured observers' investigation of the cotton bedding taken from the cage of a scent-donor conspecific. On the fifth day a clean piece of cotton bedding was given to a scent donor. On the sixth day the cotton bedding from the scent donor's cage was divided into four pieces. A piece of the used cotton bedding from the scent donor's cage was presented for each of four 3-min trials. After the 3-min trial, the bedding was discarded and 12 min later a second trial was done in the same fashion as the first but with a new piece of used bedding. This was repeated until four trials were completed. The criterion for investigation was that the subject's nose was less than $1 \mathrm{~cm}$ directly above the bedding holder. Investigation did not include standing on, gnawing or moving the holder with the paws, head or nose. The side of the holder, left or right, into which the cotton bedding was placed was kept constant for a subject but balanced for left and right sides across subjects within each of the five test conditions. The side of the holder that did not contain the conspecific's bedding remained empty. The amount of time spent investigating the bedding and empty sides of the holder were measured by an observer using a laptop computer running The Observer 5.0 (Noldus Information Technology, Sterling, Virginia, USA).

\subsection{Analyses}

Social learning of diet preference was assessed by comparing the amount of each type of food consumed by the observers. From the starting weight of each cup of cinnamon or cocoa flavored diet, subsequent weight of that cup at one hour was subtracted to yield the total grams consumed for that first hour. As needed, additional food was added to the cup at the one-hour weighing. From this new weight of the cup, the weight of the cup at four hours was subtracted to yield the total grams consumed from one to four hours. Food consumed at these two points was summed to yield total consumption over four hours. Grams of food consumed that was the same as the demonstrator's diet was divided by the total grams of food consumed from each of the two cups to yield a proportion of total food consumed that was the same as the demonstrator's diet. For each group ( 2 species $\times 5$ diet types) at each of the two time points (time of follow-up, repeated measure), $z$-scores for skewness [22] were all within \pm 0.74 . Because scores within groups were not skewed, parametric statistics were used on untransformed scores. For the unrestricted condition, these proportions were analyzed with a 2 (species) $\times 2$ (time of follow-up, repeated measure) ANOVA. Effects of nutrient restriction conditions were clearest when compared to each other and not necessarily to the unrestricted condition. The proportions of diet consumed in the nutrient 
restriction conditions were analyzed with a 2 (species) $\times 2$ (orosensory cues) $\times 2$ (rapid postingestive effects) $\times 2$ (time of follow-up, repeated measure) ANOVA. Pairwise comparisons of groups were done with Fisher's protected $t$-test.

Recognition was assessed by measuring time spent investigating repeated presentations of the bedding from a conspecific donor. Total number of seconds per trial investigating the bedding and empty halves of the bedding holder was recorded to the nearest tenth of a second. Analyses of these data were parallel to those of diet consumption. For each group ( 2 species $\times 5$ diet types) at each of the two stimuli (side of holder), $z$-scores for skewness [22] were all within \pm 0.99 . Because scores within groups were not skewed, parametric statistics were used on untransformed scores. For the unrestricted condition, these durations of investigation were analyzed with a 2 (species) $\times 4$ (trial, repeated measure) $\times 2$ (side of holder, repeated measure) ANOVA. For the nutrient restriction conditions, durations of investigation were analyzed with a 2 (species) $\times 4$ (trial, repeated measure) $\times$ 2 (side of holder, repeated measure) $\times 2$ (orosensory cues) $\times 2$ (rapid postingstive effects). To simplify presentation of data, the average differences between trials 1 and 4 are shown in figures. Additional ANOVAs pinpoint the pattern of decline in investigation in the two species. Pairwise comparisons of groups were done with Fisher's protected $t$-test.

\section{Results}

\subsection{Food Consumed by Animals with Replete Diets}

Although rats consumed on average more than five times as much of the demonstrator's diet as the other diet, hamsters tended to avoid the demonstrator's diet, consuming only about half as much of it as they consumed of the other diet (Figure 1 and Figure 2). The species difference in demonstrator's diet consumed of 48.9 percentage points that emerged one hour into the diet choice test continued through four hours of that test (main effect of species: $F_{1,9}=20.34, p<0.001$; interaction of species $\times$ time of follow up: $F_{1,9}=0.23, p=0.65$; effect of species at 1 hour: Fisher's protected $t=3.55, d f=9, p<0.01$; effect of species at four hours: Fisher's protected $t=$ 3.68, $d f=9, p<0.01)$.

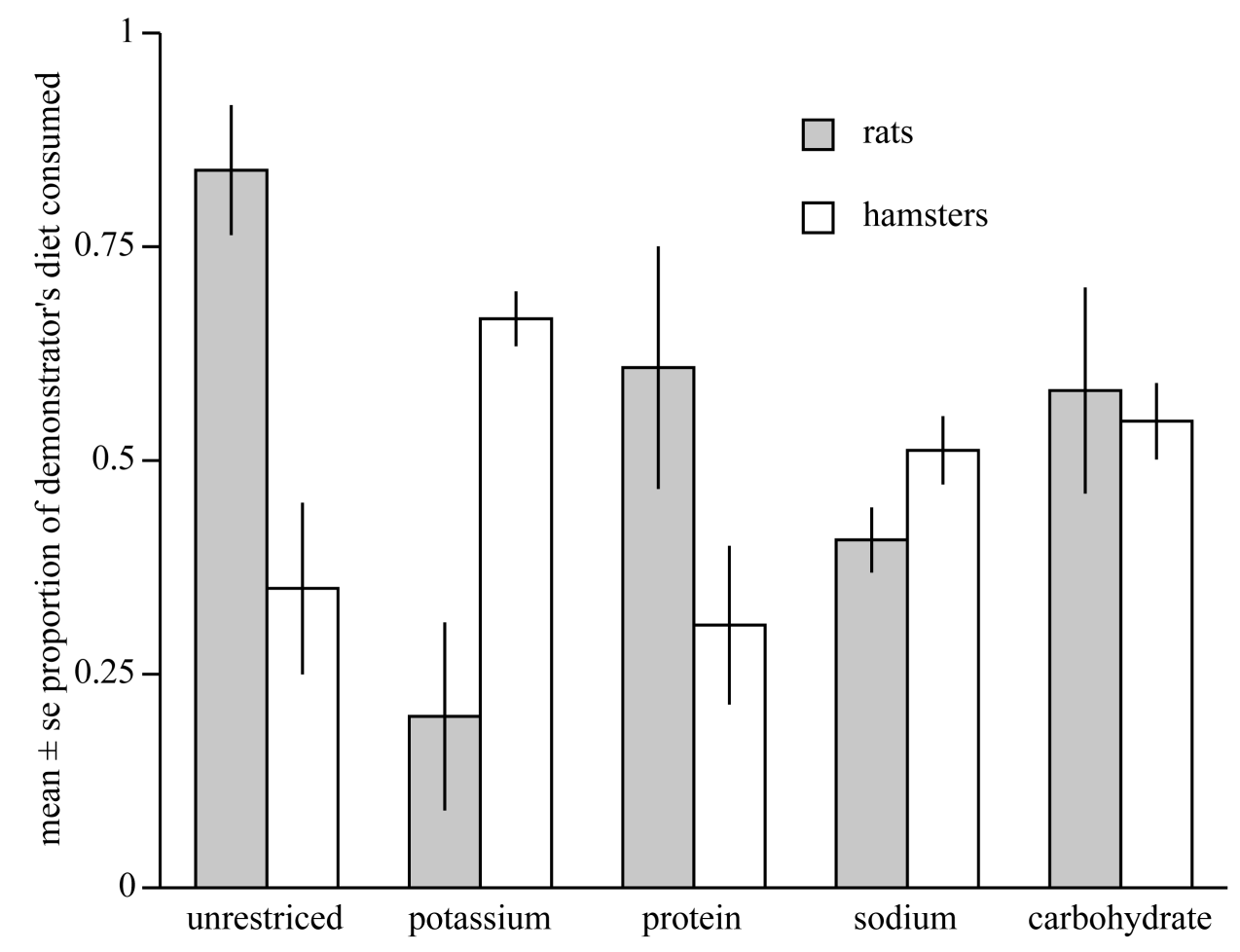

Figure 1. Mean \pm se proportion of demonstrator's diet consumed during the first hour of choice between diets with two distinct flavors. Pairs of bars represent performance of each species when restricted of one of four nutrients. Animals in the unrestricted condition had replete diets. 


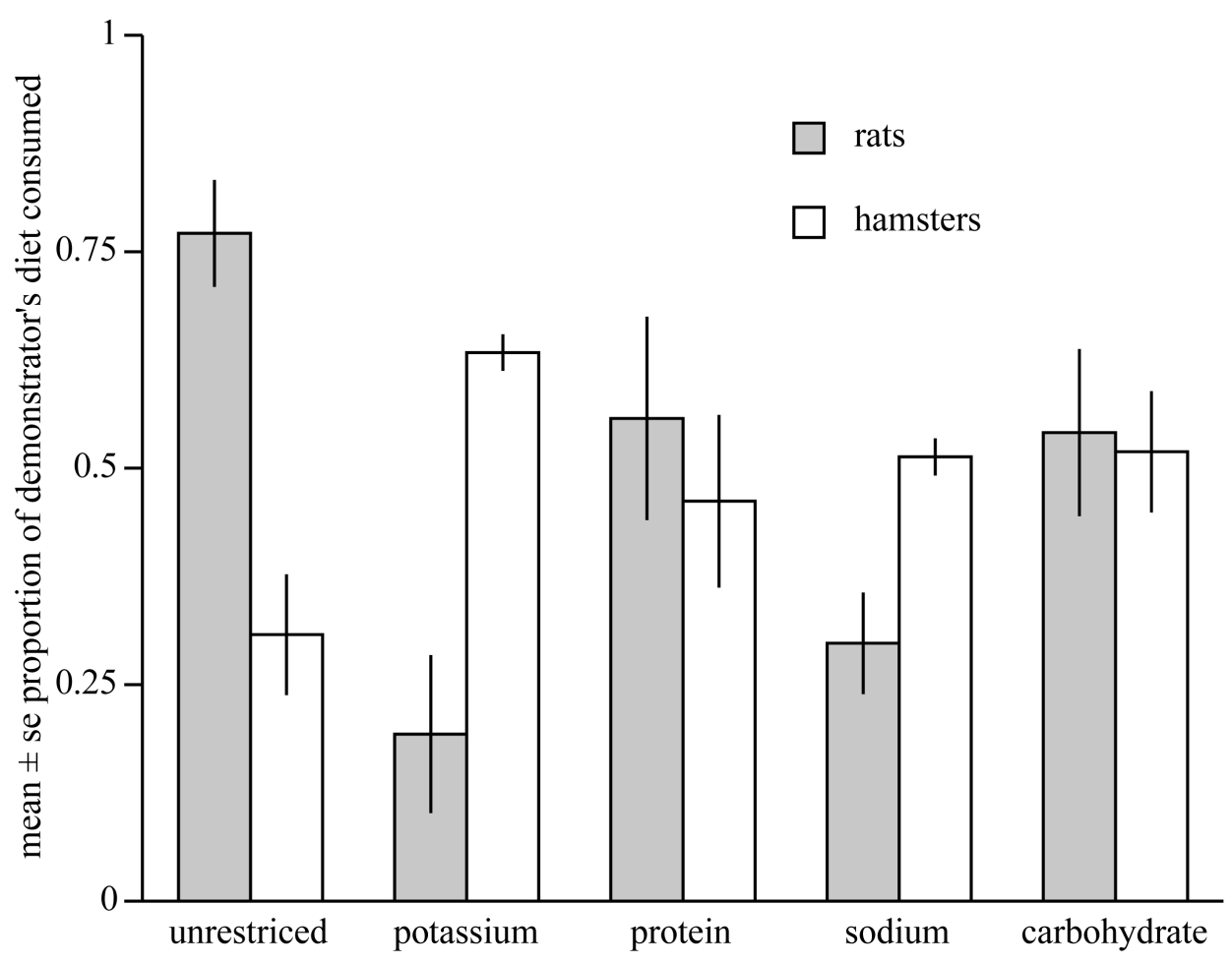

Figure 2. Mean \pm se proportion of demonstrator's diet consumed during the first four hours of choice between diets with two distinct flavors. Pairs of bars represent performance of each species when restricted of one of four nutrients. Animals in the unrestricted condition had replete diets.

\subsection{Food Consumed after One Hour by Animals with Nutrient Restriction}

Proportion of the demonstrator's diet consumed one hour into the choice test depended on species and on nutrient restriction (ANOVA three-way interaction of species, orosensory cues, and postingestive effects: $F_{1,35}=$ $6.05, p=0.02$ ). If the nutrient from which animals were restricted was more easily detectable via orosensory cues (Figure 1; sodium, carbohydrate), there was no main effect of nutrient type or of species on proportion of the demonstrator's diet consumed, nor did the effect of nutrient type interact with species (all $F \mathrm{~s}_{1,17} \leq 1.81$, $p \mathrm{~s} \geq$ 0.20). This result suggests that differences in speed of postingestive effects of sodium and carbohydrates did not influence use of social information about diet. On the other hand, if the nutrient was difficult to detect via orosensory cues (Figure 1; potassium, protein), then the influence of the demonstrator's diet depended on species and on nutrient type (interaction of species $\times$ nutrient type: $F_{1,18}=13.87, p=0.002$ ). To understand this interaction, consider first differences between species. Protein-restricted animals used social information in essentially the same way as did animals fed replete diets, rats consuming 30 percentage points more of the demonstrator's diet than hamsters consumed (Fisher's protected $t=2.39, d f=35, p<0.05$ ). It is surprising that potassium restriction resulted in a reversal of the species difference observed in animals with replete diets. Potassium-restricted rats consumed 46 percentage points less of the demonstrator's diet as compared to potassium-restricted hamsters (Fisher's protected $t=3.38, d f=35, p<0.002$ ). Consider now the within-species effects of nutrient restriction. Potassium-restricted rats consumed only one-third as much of the demonstrator's diet as did the protein-restricted rats (Fisher's protected $t=3.09, d f=35, p<0.01$ ); potassium-restricted hamsters consumed more than twice as much of the demonstrator's diet than did protein-restricted hamsters (Fisher's protected $t=2.72, d f=$ $35, p<0.02)$.

\subsection{Food Consumed after 4 Hours by Animals with Nutrient Restriction}

The four-way interaction of species, nutrient size, nutrient taste, and time $\left(F_{1,35}=5.56, p=0.02\right)$ indicates that the patterns of diet choice that were measured four hours after the choice test began were different from those measured one hour after the choice test began. 
The pattern of consumption four hours after the choice test began was parallel to that at one hour, with the exception of protein-restricted hamsters whose proportion of demonstrator's diet consumed had risen. If the nutrient from which animals were restricted was more easily detectable via orosensory cues (Figure 2; sodium, carbohydrate), there was no main effect of nutrient type or of species, nor did the effect of nutrient type interact with species (all $F s_{1,17} \leq 3.03$, $p s \geq 0.10$ ). Again, this result suggests that differences in postingestive effects did not influence use of social information about diet. On the other hand, if the nutrient was difficult to detect via orosensory cues (Figure 2; potassium, protein), then the influence of the demonstrator's diet depended on species and on nutrient type (interaction of species and nutrient type, $F_{1,19}=9.27, p=0.007$ ). To understand this interaction, consider first the differences between species. For protein-restricted animals, the difference between species had diminished to only 10 percentage points (Fisher's protected $t=0.88, d f=36, p>0.05$ ). Potassium restriction continued to result in a reversal of the species difference observed in animals with replete diets. Potassium-restricted rats consumed 44 percentage points less of the demonstrator's diet as compared to potassium-restricted hamsters (Fisher's protected $t=3.55, d f=36, p<0.002$ ). Consider now the within-species effects of nutrient restriction. Although potassium-restricted rats consumed 40 percentage points less of the demonstrator's diet as compared to protein-restricted rats (Fisher's protected $t=2.76, d f=36, p<0.01$ ), potassium- and protein-restricted hamsters did not differ in the amount of the demonstrator's diet consumed (Fisher's protected $t=1.34, d f=36, p>0.05$ ).

\subsection{Investigation of Bedding from Conspecific}

Animals investigated the portion of the bedding holder that contained bedding more than they investigated the empty portion (side of holder: unrestricted condition: $F_{1,27}=57.81, p<0.001$; nutrient-restricted conditions: $F_{1,36}$ $=72.31, p<0.001$ ). From trials 1 to 4 , members of both species in all test conditions decreased investigation of the bedding holder (trial: unrestricted condition: $F_{3,27}=16.70, p<0.001$; nutrient-restricted conditions: $F_{3,108}=$ 21.56, $p<0.001$ ). The decline was more dramatic for the bedding as compared to the empty half of the bedding holder (interaction of trial $\times$ side of holder: unrestricted condition: $F_{3,27}=10.75, p<0.001$; nutrient-restricted conditions: $F_{3,108}=13.63, p<0.001$ ), indicating that the animals habituated to the bedding and not just to the testing procedure. This is evident in the number of seconds of decrease in investigation from trial 1 to trial 4 (trial 1 minus trial 4) in Figure 3 for rats and Figure 4 for hamsters. For all conditions, analysis of

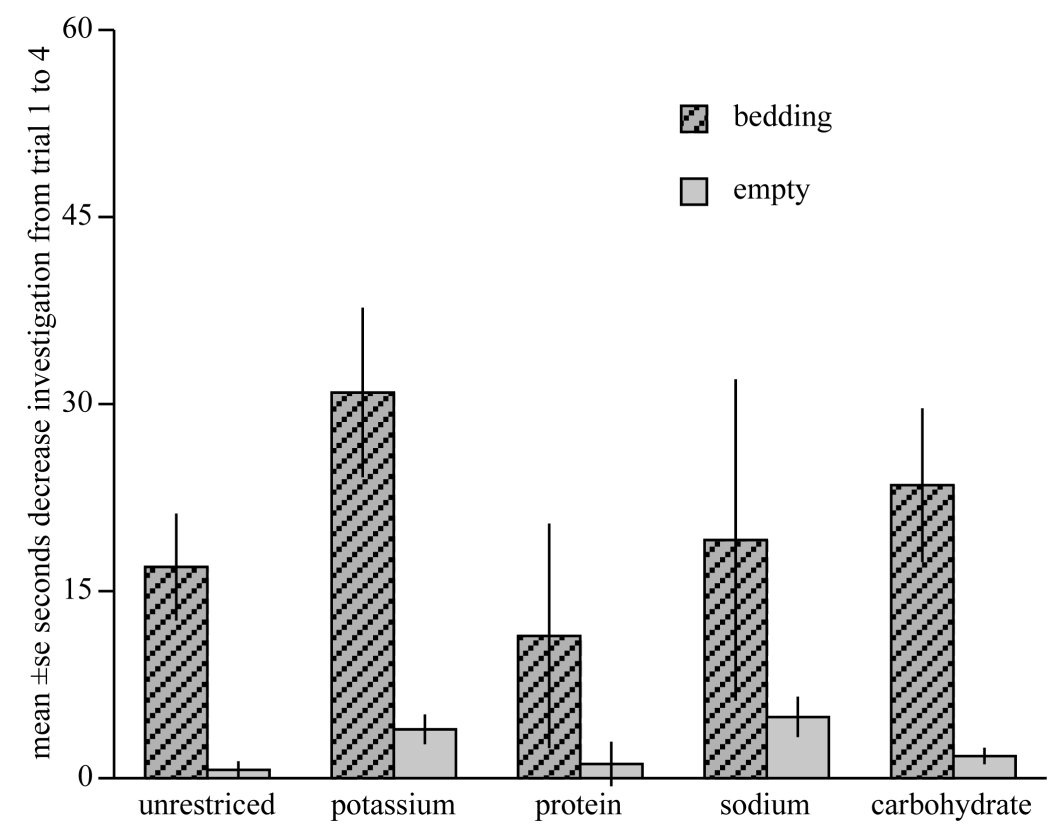

Figure 3. Mean \pm se decrease in seconds of investigation (sniffing) from the first to the fourth presentation of cotton bedding from a conspecific scent donor. Pairs of bars represent the two sides of the bedding holder for rats in each condition of dietary restriction. Animals in the unrestricted condition had replete diets. 


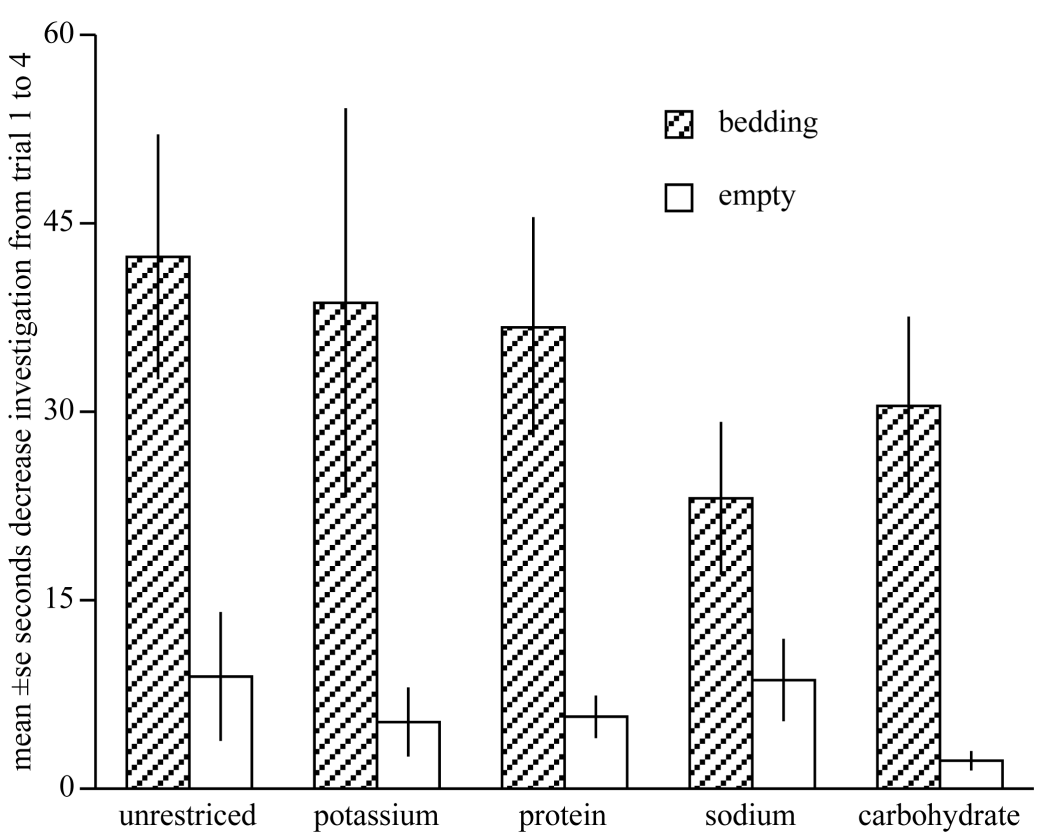

Figure 4. Mean \pm se decrease in seconds of investigation (sniffing) from the first to the fourth presentation of cotton bedding from a conspecific scent donor. Pairs of bars represent the two sides of the bedding holder for hamsters in each condition of dietary restriction. Animals in the unrestricted condition had replete diets.

the percentage of decrease from trial 1 revealed that the decline for the bedding $(76.34 \% \pm 5.15 \%)$ was greater than was the decline for the empty half $\left(50.24 \% \pm 8.91 \%\right.$; trial $\times$ side of holder interaction: $F_{1,45}=7.39, p=$ 0.009). The differential decline across trials in investigation for the two sides of the bedding holder did not depend on species $\left(F_{3,135}=1.26, p=0.29\right)$, test condition $\left(F_{12,135}=0.52, p=0.90\right)$, or the combination of species and test condition (interaction of species $\times$ nutrient restriction: $F_{12,135}=0.82, p=0.63$ ). The decline in overall investigation (bedding plus empty halves) did depend on species (interaction of species $\times$ trial: $F_{3,135}=2.77, p<$ 0.04). This is because hamsters investigated longer on trial 1 than did rats $(48.87 \pm 4.61 \mathrm{sec}$ vs $30.95 \pm 2.72 \mathrm{sec}$; Fisher's protected $t=3.07, d f=45, p<0.01$ ) but the two species did not differ in investigation on trial 4 (8.31 \pm $1.64 \mathrm{sec}$ vs $8.57 \pm 2.92 \mathrm{sec}$; Fisher's protected $t=0.04, d f=45, p>0.05$ ). The greater investigation time by hamsters on trial 1 as compared to rats on trial 1 is reflected in the larger difference between trial 1 and trial 4 shown in Figure 3 (rats) and Figure 4 (hamsters).

\section{Discussion}

Three major findings are summarized here and then each is discussed in more detail below. First, nutrient restriction was not necessary to induce members of a solitary species, Syrian hamsters, to use public information. Unexpectedly, however, Syrian hamsters ate substantially less of a demonstrator's diet than Norway rats did. Second, restriction from nutrients with readily available orosensory cues (sodium, carbohydrates) did not produce species differences in reliance on public information. Species difference in reliance on public information emerged only when the nutrient from which subjects were deprived was difficult to detect through personal experience (potassium, protein). Third, any lack of reliance on public information, was not the result of a general deficit in recognition memory brought on by deprivation of any of the specific nutrients.

The influence of public information on food consumption was different for a solitary species, Syrian hamsters, as compared to a social species, Norway rats. For animals that had been consuming replete diets, rats preferred the diet that they smelled on the breath of a conspecific, a finding that is consistent with previous studies [6]. Syrian hamsters fed replete diets, however, avoided the diet that they smelled on the breath of a conspecific. Thus, nutrient restriction is not necessary for members of a solitary species to use public information to inform their dietary choice. The surprising finding was that the influence was opposite to that observed in Norway rats: all hamsters avoided the diet that they smelled on the breath of another unfamiliar adult hamster. Previously no 
effect of public information on diet choice in hamsters was reported when that public information came from an unrelated adult or a littermate. Hamsters, however, did prefer the demonstrator's diet when the demonstrator was their mother [12]. In comparison, moderately social gerbils did not use public information regarding diet because they seemed to be made anxious by an unfamiliar, unrelated demonstrator [11] [23]. For the current study, we speculate that public information may have had a different valence for hamsters as compared to the valence it had for rats. Results of the current study parallel the responses of rats and hamsters to conspecifics that were conditioned stimuli [24]. When a conspecific was the conditioned stimulus predicting food, rats directed social behavior to another rat, but hamsters avoided another hamster. That the behavioral task used here is arousing is corroborated by reports of the roles of limbic structures in social transmission of food preferences [25]-[27].

In the study reported here, nutrient restriction affected the use of public information in a manner that depended not only on the species but also on the particular nutrient lacking in the diet. Rats and hamsters deprived of sodium or carbohydrate, which they were likely to easily detect via orosensory cues, did not appear to use public information. These orosensory cues were probably the taste of the small amount of salt or simple sugars (estimated between 2\% and 8\% of calories) in the available food (Harlan Teklad 2018 data sheet, n.d.; Harlan Teklad, Inc. personal communication) [28] [29]. Although public information is presumably lower in cost than is personal information about potential food items, personal information from orosensory cues did override reliance on public information. These current findings parallel other findings that rats deprived of sodium were unlikely to use public information and consumed less of a diet they smelled on the breath of a conspecific than did rats deprived of protein [20]. The data reported here also extend our knowledge of the effects of other nutrient deprivation on use of public information. Restriction from protein in the diet resulted in use of public information just as animals with replete diets have done. For both species, restriction from other nutrients, however, also affected the use of public information.

In contrast to animals deprived of sodium or carbohydrates, rats and hamsters deprived of protein or of potassium, which they were unlikely to detect via orosensory cues, differed dramatically in their use of public information. Rats deprived of protein ate more of the demonstrator's diet than did hamsters. For potassium, however, a surprising finding was that the species difference was reversed: rats deprived of potassium ate less of the demonstrator's diet than did hamsters. Even relatively rapid postingestive effect of potassium [30], which would be the best information about the suitability of a food and was likely available to the potassium-deprived animals, was not sufficient to override public information. This is consistent with the view that rats deficient in potassium cannot detect that mineral via orosensory cues [31]. Potassium deprivation reversed preference for familiar diet to preference of a novel diet [32]. Our results bear a superficial similarity to that pattern. For both species, potassium deprivation reversed the influence of public information on diet choice. This reversal in use of public information occurred after only a few days of deprivation. Further investigation into this surprising reversal of use of public information is warranted.

It is doubtful that nutrient restriction techniques used in this and other studies of social learning rendered animals unable to use social information. Subjects' capability of forming olfactory memories was revealed by habituation to social olfactory stimuli, the recognition of familiarity depending on memory [33]. Investigation of the bedding of a conspecific declined across trials more dramatically than the investigation of the empty area of the bedding holder declined. Failure to habituate would have indicated a failure of memory for social stimuli [34]. Thus, the lack of reliance on public information by sodium- and carbohydrate-deprived rats and hamsters was not due to a general deficit in olfactory memory.

\section{Acknowledgements}

We thank Dr. G. Privitera and three anonymous reviewers for their comments. This project was supported in part by a faculty research grant from St. Bonaventure University to D. J. Mayeaux.

\section{References}

[1] Danchin, E., Giraldeau, L.A., Valone, T.J. and Wagner, R.H. (2004) Public Information: From Nosy Neighbors to Cultural Evolution. Science, 305, 487-491. http://dx.doi.org/10.1126/science.1098254

[2] Valone, T.J. (2007) From Eavesdropping on Performance to Copying the Behavior of Others: A Review of Public Information Use. Behavioral Ecology and Sociobiology, 62, 1-14. http://dx.doi.org/10.1007/s00265-007-0439-6

[3] Boyd, R. and Richerson, P.J. (1988) An Evolutionary Model of Social Learning: The Effects of Spatial and Temporal 
Variation. In: Zentall, T.R. and Galef Jr., B.G., Eds., Social Learning: Psychological and Biological Perspectives, Lawrence Erlbaum Associates, Hillsdale, 29-48.

[4] Ward, P. and Zahavi, A. (1973) The Importance of Certain Assemblages of Birds as "Information Centres" for Food-Finding. Ibis, 115, 517-534. http://dx.doi.org/10.1111/j.1474-919X.1973.tb01990.x

[5] Galef Jr., B.G. (2009) Strategies for Social Learning: Testing Predictions from Formal Theory. Advances in the Study of Behavior, 39, 117-151. http://dx.doi.org/10.1016/S0065-3454(09)39004-X

[6] Galef Jr., B.G. (2012) Social Learning in Rats. In: Zentall, T.R. and Wasserman, E.A., Eds., The Oxford Handbook of Comparative Cognition, Oxford University Press, New York, 803-818.

[7] Kao, A.B., Miller, N., Torney, C., Hartnett, A. and Couzin, I.D. (2014) Collective Learning and Optimal Consensus Decisions in Social Animal Groups. PLoS Computational Biology, 10.

[8] Strupp, B.J. and Levitski, D.A. (1984) Social Transmission of Food Preferences in Adult Hooded Rats (Rattusnorvegicus). Journal of Comparative Psychology, 98, 257-266. http://dx.doi.org/10.1037/0735-7036.98.3.257

[9] Galef Jr., B.G. and Wigmore, S.W. (1983) Transfer of Information Concerning Distant Foods: A Laboratory Investigation of the "Information-Centre" Hypothesis. Animal Behaviour, 31, 748-758. http://dx.doi.org/10.1016/S0003-3472(83)80232-2

[10] Forkman, B. (1991) Social Facilitation Is Shown by Gerbils When Presented with Novel but Not with Familiar Foods. Animal Behaviour, 42, 860-861. http://dx.doi.org/10.1016/S0003-3472(05)80132-0

[11] Valsecchi, P., Choleris, E., Moles, A., Guo, C. and Mainardi, M. (1996) Kinship and Familiarity as Factors Affecting Social Transfer of Food Preferences in Adult Mongolian Gerbils (Meriones unguiculatus). Journal of Comparative Psychology, 110, 243-251. http://dx.doi.org/10.1037/0735-7036.110.3.243

[12] Lupfer, G., Frieman, J. and Coonfield, D. (2003) Social Transmission of Flavor Preferences in Two Species of Hamsters (Mesocricetus auratus and Phodopus campbelli). Journal of Comparative Psychology, 117, 449-455. http://dx.doi.org/10.1037/0735-7036.117.4.449

[13] Rymer, T., Schradin, C. and Pillay, N. (2008) Social Transmission of Information about Novel Food in Two Populations of the African Striped Mouse, Rhabdomys pumilio. Animal Behaviour, 76, 1297-1304. http://dx.doi.org/10.1016/j.anbehav.2008.06.014

[14] Tarini, A., Bakari, S. and Delisle, H. (1999) The Overall Nutritional Quality of the Diet Is Reflected in the Growth of Nigerian Children. Santé, 9, 23-31.

[15] Jiang, T., Christian, P., Khatry, S.K., Wu, L. and West Jr., K.P. (2005) Micronutrient Deficiencies in Early Pregnancy are Common, Concurrent and Vary by Season among Rural Nepali Pregnant Women. American Society for Nutritional Sciences, 135, 1106-1112.

[16] Ali, A., Abdel-Razek, A.K., Derar, R., Abdel-Rheem, H.A. and Shehata, S.H. (2009) Forms of Reproductive Disorders in Cattle and Buffaloes in Middle Egypt. Reproduction in Domestic Animals, 44, 580-586. http://dx.doi.org/10.1111/j.1439-0531.2007.01022.x

[17] Galef Jr., B.G., Beck, M. and Whiskin, E.E. (1991) Protein Deficiency Magnifies Social Influence on the Food Choices of Norway Rats (Rattus norvegicus). Journal of Comparative Psychology, 105, 55-59. http://dx.doi.org/10.1037/0735-7036.105.1.55

[18] Galef Jr., B.G. (1991) A Contrarian View of the Wisdom of the Body as It Relates to Dietary Self-Selection. Psychological Review, 98, 218-223. http://dx.doi.org/10.1037/0033-295X.98.2.218

[19] Kyriazakis, I., Tolkamp, B.J. and Emmans, G. (1999) Diet Selection and Animal State: An Integrative Framework. The Proceedings of the Nutrition Society, 58, 765-772. http://dx.doi.org/10.1017/S0029665199001044

[20] Galef Jr., B.G. and Whiskin, E.E. (2008) Use of Social Information by Sodium- and Protein-Deficient Rats: Test of a Prediction (Boyd \& Richerson 1988). Animal Behaviour, 75, 627-630. http://dx.doi.org/10.1016/j.anbehav.2007.06.023

[21] Ruiz-Opazo, N., Lopez, L.V. and Tonkiss, J. (2004) Modulation of Learning and Memory in Dahl Rats by Dietary Salt Restriction. Hypertension, 43, 797-802. http://dx.doi.org/10.1161/01.HYP.0000120153.04064.8d

[22] Tabachnick, B.G. and Fidell, L.S. (2001) Using Multivariate Statistics. Allyn and Bacon, Boston.

[23] Choleris, E., Valsecchi, P., Wang, Y., Ferrari, P., Kavaliers, M. and Mainardi, M. (1998) Social Learning of a Food Preference in Male and Female Mongolian Gerbils Is Facilitated by the Anxiolytic, Chlordiazepoxide. Pharmacology, Biochemistry and Behavior, 60, 575-584. http://dx.doi.org/10.1016/S0091-3057(98)00005-7

[24] Timberlake, W. (1983) The Functional Organization of Appetitive Behavior: Behavior Systems and Learning. In: Zeiler, M.D. and Harzem, P., Eds., Advances in Analysis of Behaviour, Vol. 3, John Wiley \& Sons Ltd., New York, 177-217.

[25] Wang, Y., Fontanini, A. and Katz, D.B. (2006) Temporary Basolateral Amygdala Lesions Disrupt Acquisition of Socially Transmitted Food Preferences in Rats. Learning \& Memory, 13, 794-800.

[26] Carballo-Márquez, A., Vale-Martínez, A., Guillazo-Blanch, G. and Martí-Nicolovius, M. (2009) Muscarinic Receptor 
Blockade in Ventral Hippocampus and Prelimbic Cortex Impairs Memory for Socially Transmitted Food Preference. Hippocampus, 19, 446-455. http://dx.doi.org/10.1002/hipo.20530

[27] Carballo-Márquez, A., Vale-Martínez, A., Guillazo-Blanch, G. and Martí-Nicolovius, M. (2009) Muscarinic Transmission in the Basolateral Amygdala Is Necessary for the Acquisition of Socially Transmitted Food Preferences in Rats. Neurobiology of Learning and Memory, 91, 98-101. http://dx.doi.org/10.1016/j.nlm.2008.09.014

[28] United States Department of Agriculture Nutrient Database. http://ndb.nal.usda.gov/

[29] Sauvant, D., Perez, J.-M. and Tran, G. (2004) Tables of Composition and Nutritive Value of Feed Materials: Pigs, Poultry, Cattle, Sheep, Goats, Rabbits, Horses, Fish. INRA Editions, Wageningen Academic Publishers, Versailles. http://dx.doi.org/10.3920/978-90-8686-668-7

[30] Milner, P. and Zucker, I. (1965) Specific Hunger for Potassium in the Rat. Psychonomic Science, 2, 17-18. http://dx.doi.org/10.3758/BF03343307

[31] Guenthner, C.J., McCaughey, S.A., Tordoff, M.G. and Baird, J.P. (2008) Licking for Taste Solutions by PotassiumDeprived Rats: Specificity and Mechanisms. Physiology \& Behavior, 93, 937-946. http://dx.doi.org/10.1016/j.physbeh.2007.12.017

[32] Adam, W.R. (1973) Novel Diet Preferences in Potassium-Deficient Rats. Journal of Comparative \& Physiological Psychology, 84, 286-288. http://dx.doi.org/10.1037/h0035274

[33] Hughes, R.N. (2007) Neotic Preferences in Laboratory Rodents: Issues, Assessment and Substrates. Neuroscience and Biobehavioral Reviews, 31, 441-464. http://dx.doi.org/10.1016/j.neubiorev.2006.11.004

[34] Blackford, J.U., Allen, A.H., Cowan, R.L. and Avery, S.N. (2013) Amygdala and Hippocampus Fail to Habituate to Faces in Individuals with an Inhibited Temperament. Social Cognitive and Affective Neuroscience, 8, 143-150. http://dx.doi.org/10.1093/scan/nsr078 
Scientific Research Publishing (SCIRP) is one of the largest Open Access journal publishers. It is currently publishing more than 200 open access, online, peer-reviewed journals covering a wide range of academic disciplines. SCIRP serves the worldwide academic communities and contributes to the progress and application of science with its publication.

Other selected journals from SCIRP are listed as below. Submit your manuscript to us via either submit@scirp.org or Online Submission Portal.
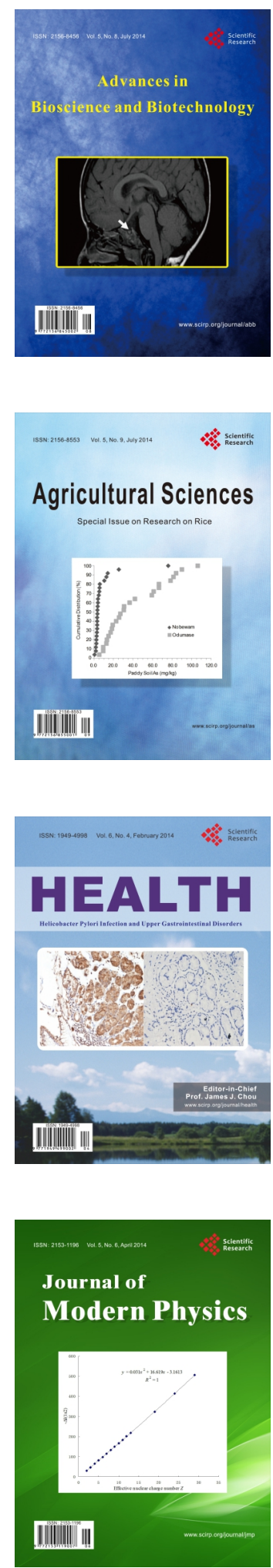
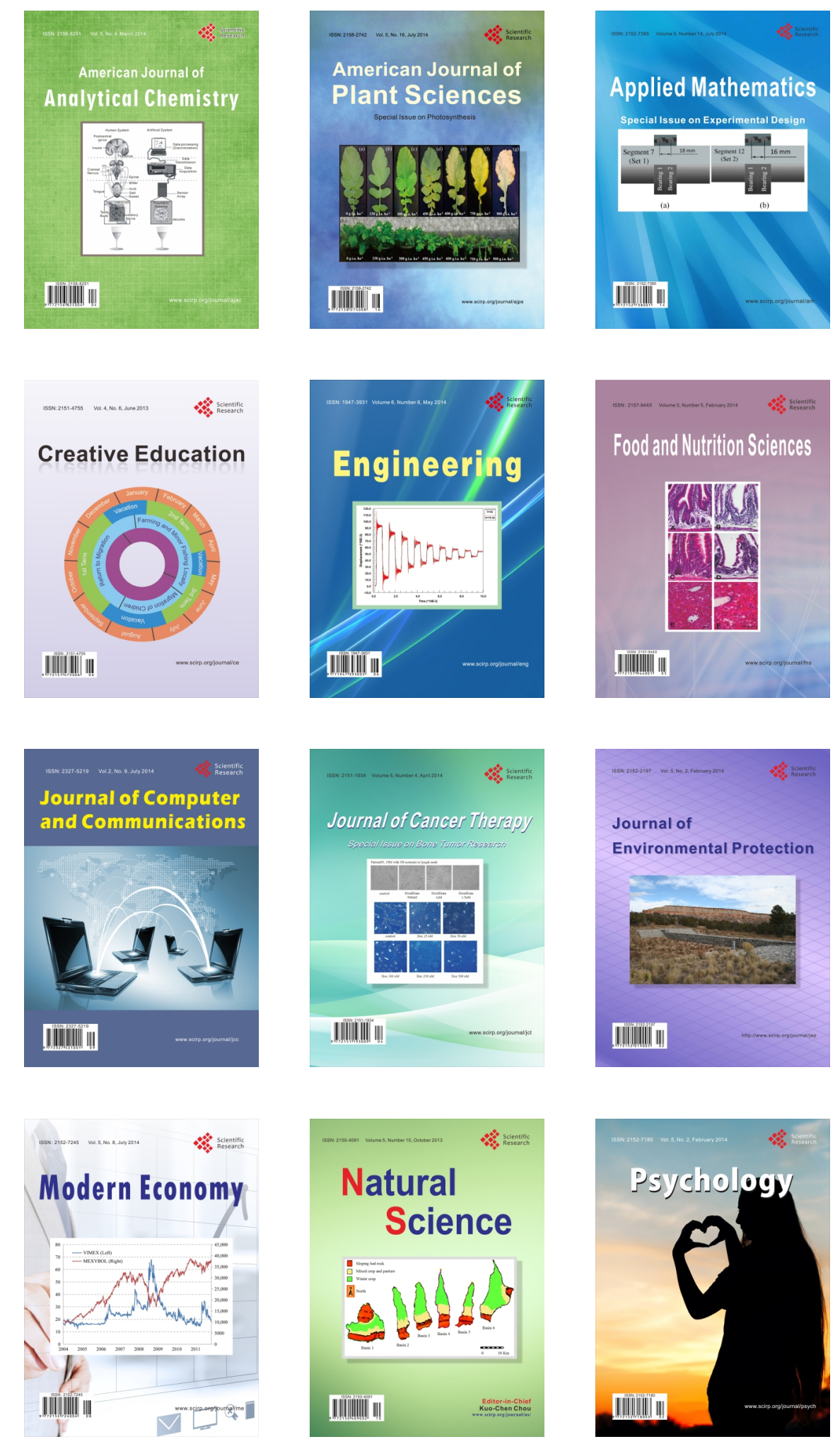